\title{
SURGICAL TREATMENT OF CHRONIC DISLOCATION OF THE PERONEAL TENDONS
}

\author{
P. SLÄTIS, S. SANTAVIRTA and J. SANDELIN \\ The Orthopaedic Hospital of Invalid Foundation and University Central Hospital, Helsinki, Finland
}

\section{ABSTRACT}

Recent reports on the outcome of sports injuries have pointed out that ankle sprains may cause long term discomfort, this occasionally being due to peroneal tendon dislocation which may become chronic. The present paper reports a method, which includes deepening of the retromalleolar groove and at the same time maintaining the cartilagenous gliding layer. Long term follow-up (2 to 10 years) is presented on four patients. One of the patients returned successfully to international track and road races. In each case, the clinical result after the operation was successful, the ankles showing normal biomechanical functions.

Key words: Peroneal tendon dislocation, Ankle injuries

Peroneal tendon dislocation is relatively uncommon, although some authors have suggested that acute peroneal tendon dislocations could be incorrectly diagnosed at the acute stage as simple ankle sprains (Marti, 1977). Severe ankle sprains often result in long term discomfort in athletes and some of these injuries are probably overlooked cases of peroneal tendon dislocation which with time recur or become chronic (Sandelin et al, 1985).

The mechanism of the primary injury remains in part in dispute. It has been suggested that the tendon luxation occurs when the foot is in dorsiflexion and either in inversion or in eversion (Allaria and Franz, 1953; Stover and Bryan, 1962). It has also been suggested that forceful peroneal contraction is essential, the foot being either in maximal dorsiflexion or plantar flexion (Marti, 1977). In a number of cases, peroneal luxation has been reported secondary to skiing injuries but it seems less common in track and field athletes. In chronic dislocation of the peroneal tendons, the superior peroneal retinaculum is ruptured, the tendons are dislocated from the retromalleolar groove and present sometimes as painful chronic tenosynovitis (Figs. 1, 2 and 3A).
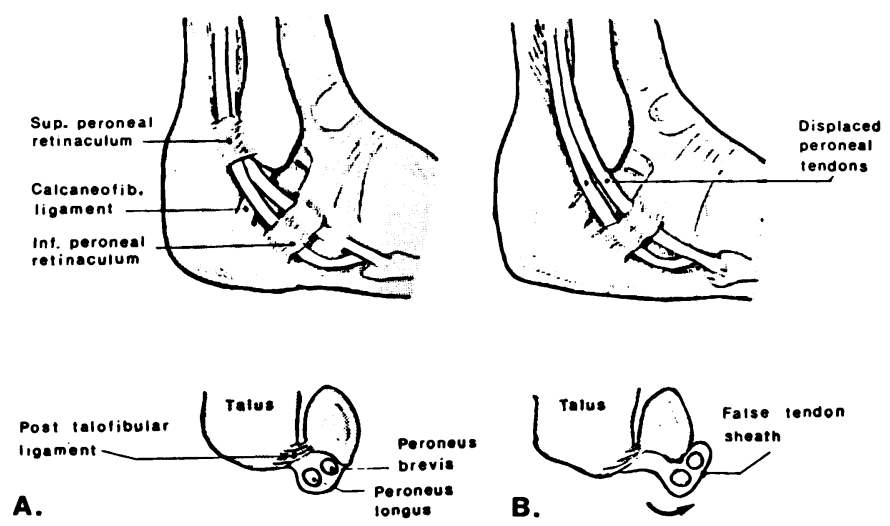

Fig. 1A-B: Schematic drawing of the normal anatomy of the peroneal tendons and dislocation of the peroneal tendons from the retromalleolar groove. The superior peroneal retinaculum is ruptured and the dislocated tendons are covered with scar tissue which mimics false tendon sheath.

\section{Address for correspondence:}

Seppo Santavirta, MD

Orthopaedic Hospital of Invalid Foundation

Tenholantie 10

00280 Helsinki

Finland

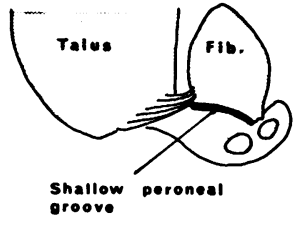

A.

Fig. 2A-C: The authors' method of surgical repair of chronic dislocation of the peroneal tendons. The retromalleolar groove is reshaped and the cartilagenous gliding layer is at the same time maintained.

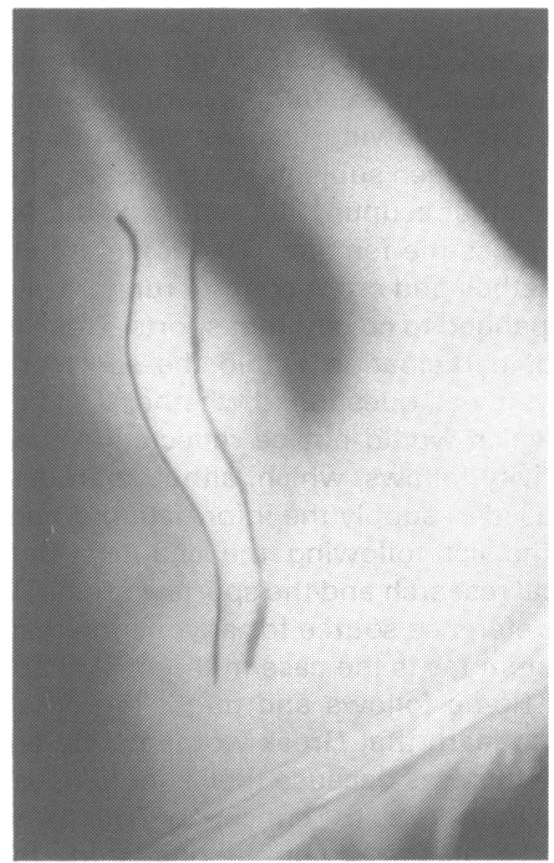

Fig. 3A: Preoperative photograph of anteriorly displaced peroneal tendons (Case 2).

Many operative methods have been developed to treat chronic dislocation of the peroneal tendons. Our objective was to report long term results in athletes following an operation which restores the natural biomechanics of the peroneal tendons.

\section{SURGICAL PROCEDURE}

The incision is made at the posterior edge of the fibula and curved around the lateral malleolus in an anterior direction. The subcutaneous tissues are divided and if the peroneal tendon sheath is intact, it is opened and the tendons are 
retracted anteriorly over the lateral malleolus (Fig. 3B). The cartilage layer of the retromalleolar groove with some subchondral bone is then carefully detached with a chisel. Further subchondral cancellous bone is removed with a curved chisel and thus the groove is deepend. The cartilage layer is then pressed onto the cancellous surface of the deepened retromalleolar groove. The peroneal tendons are bought back into position in the reshaped groove (Fig. $3 \mathrm{C}$ ). In cases of existing tenosynovitis, tenosynovectomy is additionally performed. When feasible, an overstretched peroneal sheath and ruptured retinaculum are reconstructed. Postoperatively, the ankle is immobilised for six weeks in a below-knee plaster cast. Return to normal exercise is allowed at three months.

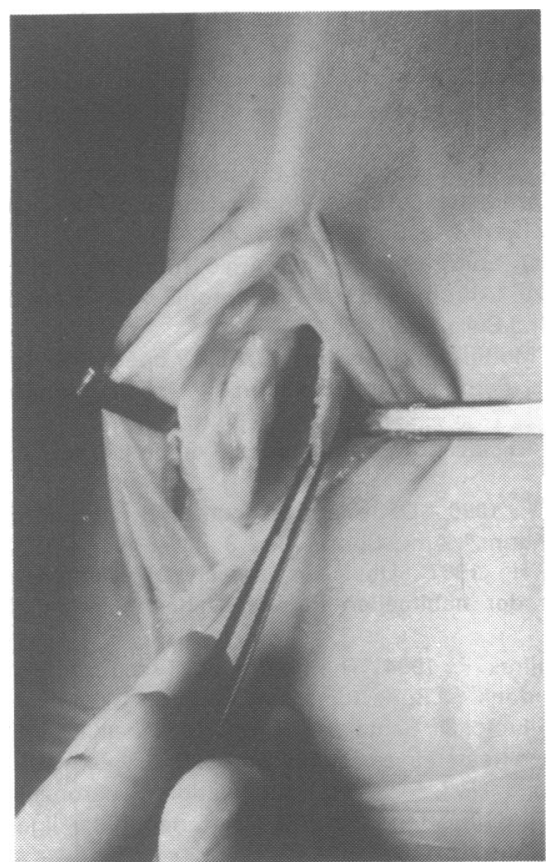

Fig. 3B: During the operation, peroneal tendons are retracted anteriorly, the cartilagenous layer (forceps) of the retromalleolar groove is carefully detached with chisel and the groove is deepened.

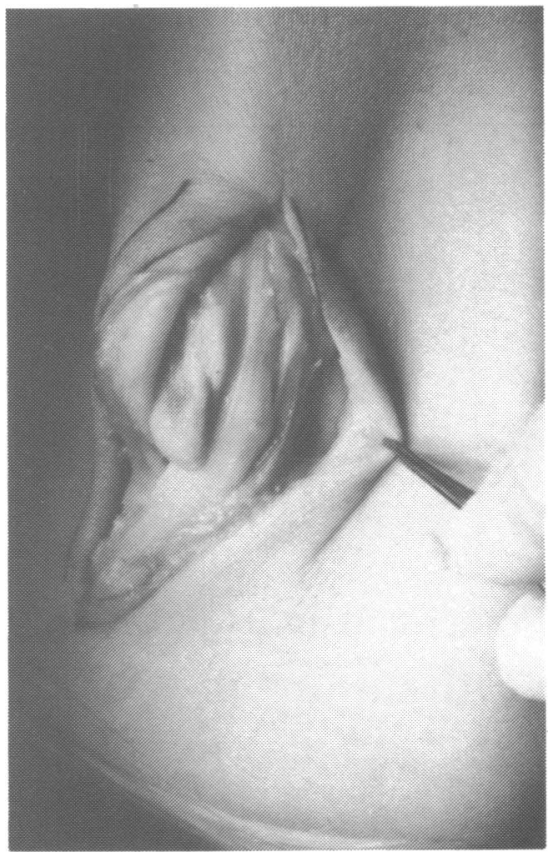

Fig. 3C: The cartilage is then pressed onto the cancellous surface of the reshaped groove and the peroneal tendons are brought back to their anatomic position.

\section{CASE REPORTS}

\section{Case 1}

The patient was a 27-year-old Finnish top class long distance runner. While deer hunting in September 1976, he suffered a sprain of his right ankle. The lateral malleolar region remained swollen and tender, local pain preventing the patient from running. Chronic dislocation of the peroneal tendons was diagnosed and the patient was operated on using the procedure described above on 14 December, 1976. The postoperative course was favourable and four months after the operation he participated in a $25 \mathrm{~km}$ competition. During the European summer season 1977, he was able to join the Finnish national track team again.

In a follow-up examination in March 1987, he reported that he had been without any ankle related discomfort during the past 10 years and still participated in road races. Interestingly, he is now able to demonstrate a voluntary peroneal tendon subluxation in the contralateral ankle, this being, however, asymptomatic.

\section{Case 2}

A 27-year-old ice-hockey player was tackled in a game in December 1982 and suffered a sprain of his left ankle. The ankle remained painful during exercise and skating was painful. Three years later the patient sought advice for this discomfort at an orthopaedic out-patient clinic, where chronic dislocation of the peroneal tendons were diagnosed (Fig. 3A). The operation was performed on 15 April, 1985. The patient returned two months postoperatively to physically demanding work and played ice-hockey without any discomfort five months postoperatively. At follow-up examination two years postoperatively, the ankle had normal function, no swelling around the lateral malleolus and the peroneal tendons remained in all foot positions in the reshaped retromalleolar sulcus.

\section{Case 3}

A 39-year-old male tennis player who was successful at national level, suffered recurrent sprains in his left ankle during 1982. Running caused pain and discomfort around the lateral malleolus and during voluntary inversion of the ankle, peroneal tendon dislocation from the retromalleolar groove was recorded. The operation was performed on 1 February, 1983. The patient started jogging three months postoperatively and returned to tennis at four months. At follow-up in May 1987, more than 4 years after the operation, the patient reported he had been without any discomfort, the ankle appeared functionally normal and the patient practiced tennis or squash most days of the week without handicap.

\section{Case 4}

A 59-year-old woman, who is a keep-fit enthusiast, suffered a sprain of her left ankle while jogging on uneven terrain in June 1980.. The primary diagnosis at the first-aid department was sprain of the anterior fibulotalar ligament and the treatment was elastic taping for the first two weeks. After the swelling around the lateral malleolus had subsided, chronic dislocation of the peroneal tendons was diagnosed and on 3 March, 1981 the above-described operation including local tenosynovectomy of the peroneal tendons was performed. Five months postoperatively, the patient was able to begin jogging. At follow-up in May 1987, 
six years postoperatively, her sports had become more sedentary but the ankle showed normal functional biomechanics and the patient was happy with the result.

\section{DISCUSSION}

Acute dislocation of the peroneal tendons from the retromalleolar groove, is probably more prevalent than usually thought (McLennan, 1980). It is unknown, how many acute ankle sprains will result in chronic peroneal tendon dislocation. Experts in sports traumatology suggest that non-operable treatment of peroneal tendon dislocation gives satisfactory results in the majority of cases (Kalenak, 1980). However, competitive athletes and some keep-fit athletes make such high demands on their ankles that operative treatment should be considered for chronic peroneal tendon dislocation.

Numerous operations have been designed, which may indicate an unsolved problem (Pöll and Duijfjes, 1984). The Kelly (1920) procedure with an osteotomy and posterior displacement of a thick bone flap from the surface of the lateral malleolus has been advocated for treatment of recurrent peroneal dislocation (Marti, 1977). Different modifications of the original Kelly technique have been reported in the literature (Inman et al, 1978; Colton, 1982). Also the technique of deepening the retromalleolar groove has been presented previously (Justis, 1980). The calcaneofibular ligament has been used to reconstruct the superior peroneal retinaculum and Pöll and Duijfres have further improved these procedures by transposing the calcaneofibular ligament insertion with a small bone block (Leitz, 1968; Platzgummer, 1967; Pöll and Duijfjes, 1984; Sarmiento and Wolf, 1976). However, in all the above techniques the natural cartilagenous gliding layer of the tendons is destroyed and we feel that in cases of active athletes a more physiological procedure should be considered.

The method reported in the present paper was first published in 1979 (Slätis and Santavirta, Zoellner and Clancy). However, long-term results have not previously been reported. The advantage of this method is that it restores the natural biomechanics of the peroneal tendons and at the same time maintains the cartilagenous gliding layer of the retromalleolar groove. At long-term follow-up our patients have been without discomfort since the operation, one athlete having thousands of miles of successful road running and competition to his credit. At the moment we feel that the method presented here is probably the most physiological procedure for the treatment of chronic dislocation of the peroneal tendons.

\section{References}

Allaria, A. and Franz, A., 1953 "La lussazione traumatica dei muscoli peronei laterali". Minerva Orthop. 4: 203-213.

Arrowsmith, S. R., Fleming, L. and Allman, F., 1983 "Traumatic dislocations of the peroneal tendons". Am.J.Sports Med. 11: 142-146.

Colton, C. L., 1982 "Dislocation of the peroneal tendons". In: Fractures and Joint Injuries. Ed. R. Watson-Jones. New York, Churchill Livingstone. Sixth ed., pp. 1139-1140.

Inman, V. T. and Mann, R. A., 1978 "Peroneal tendon dislocation". In: Surgery of the Foot. Ed. H. DuVries. St. Louis, C. V. Mosby Company. Fourth ed. pp. 540-541.

Justis, E. J. Jr., 1980 "Dislocation of the peroneal tendons". In: Campbell's Operative Orthopaedics. Ed. A. Edmondson and A. Crenshaw. St. Louis, C. V. Mosby Company. Sixth ed., pp. 1400-1402.

Kalenak, A., 1980 "Editorial comment". Am.J.Sports Med. 8: 436.

Kelly, R. E., 1920 "An operation for the chronic dislocation of the peroneal tendons". Br.J.Surg. 7: 502-504.

Leitz, G., 1968 "Modifikation des Verfahrens zur operativen Behadndlung der habituellen Peronealsehnenluxation". Arch.Orthop.Unfallchir. 64: 245-251.

Marti, R., 1977 "Dislocation of the peroneal tendons". Am.J.Sports Med. 5: 19-22.

McLennan, J. G., 1980 "Treatment of acute and chronic luxations of the peroneal tendons". Am.J.Sports Med. 8: 432-436.

Plantzgummer, H., 1967 "Über ein einfaches Verfahren zur operativen Behandlung der habituellen Peroneussehnenluxation". Z.Orthop. 61: 144-150.

Pöll, R. and Duijfres, F., 1984 "The treatment of recurrent dislocation of the peroneal tendons". J.Bone Joint Surg. 66-B: 98-100.

Sandelin, J., Kiviluoto, O., Santavirta, S. and Honkanen, R., 1985 "Outcome of sports injuries treated in a casualty ward". Br.J.Sports Med. 11: 103-106.

Sarmiento, A. and Wolf, M., 1976 "Subluxation of peroneal tendons: case treated by rerouting tendons under calcaneofibular ligament". J.Bone Joint Surg 57-A: 115-116.

Slätis, P. and Santavirta, S., 1979 "Operative treatment for chronic dislocation of the peroneal tendons". Acta Chir.Scand, Suppl. 493: 63.

Stover, C. and Bryan, D., 1962 "Traumatic dislocation of the peroneal tendons". J.Bone Joint Surg. 61-A: 292-294.

Zoellner, G. and Glancy, W. Jr., 1979 "Recurrent dislocation of the peroneal tendons". J.Bone Joint Surg. 61-A: 292-294. 